\section{Sentinel Lymph Node Mapping and Dissection in Patients with Endometrial Cancer}

\author{
Georgios Androutsopoulos $^{1 *}$, loannis C Kotsopoulos ${ }^{2}$, Georgios Decavalas ${ }^{1}$ \\ ${ }^{1}$ Department of Obstetrics and Gynecology, University of Patras, Medical School, Rion, Greece \\ ${ }^{2}$ Northern Gynaecological Oncology Centre, Queen Elizabeth Hospital, Gateshead, United Kingdom
}

"Corresponding author: Georgios Androutsopoulos, Assistant Professor, Department of Obstetrics and Gynecology, University of Patras, Medical School, Rion 26504, Greece, Tel: +306974088092; E-mail: androutsopoulos@upatras.gr, androutsopoulosgeorgios@hotmail.com

Received Date: December 15, 2016; Accepted Date: December 23, 2016; Published Date: December 26, 2016

Copyright: (c) 2016 Androutsopoulos G, et al. This is an open-access article distributed under the terms of the Creative Commons Attribution License, which permits unrestricted use, distribution, and reproduction in any medium, provided the original author and source are credited.

\section{Endometrial Cancer}

In developed countries, endometrial cancer (EC) is the most frequent cancer of the female reproductive system [1-4]. According to the recent recommendations and guidelines, systematic surgical staging represents the primary treatment of these patients [1-4]. However, the extent of this procedure should be carefully individualized according to the histological type and the patient's general performance status [1-4].

Moreover, all these recommendations and guidelines emphasize the fact that pelvic and para-aortic lymphadenectomy is really essential in systematic surgical staging $[1,3,4]$. This is mostly because the implementation of systematic lymphadenectomy provides meaningful data regarding the necessity of postoperative treatment with a view to increase the survival and at the same time diminish the morbidity of overtreatment (e.g. side effects and toxicity related with radiotherapy and chemotherapy) and the consequences of under-treatment (recurrence) [1-4]. Nevertheless, in early stage type I EC patients, the utilization of pelvic lymphadenectomy has no effect on the overall and the disease free survival and should be avoided in daily practice [1-4].

Recently, sentinel lymph node mapping and dissection has gained popularity in EC patients [4-7]. This is mainly because that specific approach epitomizes an equilibrium between systematic and no lymphadenectomy in well selected EC patients of low and intermediate risk $[1,4-10]$.

The rational of the sentinel lymph node mapping and dissection is based on the fact that lymph follows a specific pattern to drain away from the endometrial tumor [5,9]. In particular, we inject a tracer $(99$ $\mathrm{m}$ Technetium, patent blue, indocyanine green) directly into the uterus (mainly into cervix, but also into the uterine serosa or endometrium) and we identify the sentinel lymph nodes using specific equipment $[1,5,6,9,11]$. Therefore based on the accumulation and the signal of the injected agent, we are able to identify and dissect the suspicious for metastasis lymph nodes [5-8,11].

According to the sentinel lymph node surgical algorithm, apart from the sentinel we should also remove any suspicious or enlarged lymph nodes [5]. Furthermore, if we cannot detect the sentinel lymph node on one side, a side specific pelvic, common iliac and interiliac systematic lymphadenectomy should be performed [5].

The dissected sentinel lymph nodes should be ultra-staged by the pathologist $[5,12]$. This process requires multiple sections from every lymph node combined with immunohistochemistry [5,12]. A lymph node is considered positive when contains not only macrometastasis but also micrometastasis or even isolated tumor cells [5]. In particular, in macrometastasis there are tumor clusters more than $2 \mathrm{~mm}$, while in micrometastasis the tumor clusters are between 0.2 and $2.0 \mathrm{~mm} \mathrm{[5].}$ Nevertheless, ultra-staging is time consuming, expensive and unsuitable for large numbers of lymph nodes $[5,12]$.

In patients with negative sentinel lymph nodes, there is no need for further node excision because of the low chance for distal node involvement [5,9]. In this case, we could avoid any unnecessary overtreatment by excising normal or negative lymph nodes $[5,6]$. Moreover, we could decrease the total operative time, the financial cost and the incidence of perioperative complications (nerves or vessels injury, formation of lymphocysts or lymphoedema and cellulitis) compared with the systematic lympadenectomy [1-5].

On the other hand, in positive sentinel lymph nodes patients, systematic pelvic and para-aortic lymphadenectomy is required $[4,5,9]$. In particular, we should remove the lymphatic tissue from the distal half of the common iliac vessels, the external iliac vessels and the obturator fossa, as well as from the inferior vena cava and aorta (up to the level of the renal vessels or lower to the inferior mesenteric artery) $[1,3,4]$.

Particularly in patients with early stage endometrial carcinoma, sentinel lymph node mapping could have a crucial role in the detection of nodes micrometastases, according to the SENTI-ENDO study results $[1,5,6,9,11,13,14]$. This is mainly due to the application of ultrastaging in the dissected lymph nodes $[7,8,14]$.

In conclusion, sentinel lymph node mapping and dissection represents an interesting approach in well selected EC patients [1,4,5,7-11]. Although in endometrial cancer, this approach is still experimental, it could possibly have a prominent role in the lymph node assessment, especially in early stages $[1,5,6,9,11,13,14]$. However, prospective randomized clinical trials are necessary in order to clarify whether this procedure could finally substitute the systematic lymphadenectomy in the future $[1,4,5,7,8,14]$.

\section{Conflict of Interest}

We declare that we have no conflict of interest.

\section{References}

1. Colombo N, Creutzberg C, Amant F, Bosse T, Gonzalez-Martin A, et al. (2016) ESMO-ESGO-ESTRO Consensus Conference on Endometrial Cancer: diagnosis, treatment and follow-up. Ann Oncol 27: 16-41.

2. Androutsopoulos G, Decavalas G (2016) Standard and novel therapies in endometrial cancer. J Gynecol Women's Health1: 555564.

3. ACOG (2015) ACOG practice bulletin \# 149: Endometrial cancer. Obstet Gynecol 125: 1006-1026. 
Citation: Androutsopoulos G, Kotsopoulos IC, Decavalas G (2016) Sentinel Lymph Node Mapping and Dissection in Patients with Endometrial Cancer. Trends Gynecol Oncol 1: e103.

Page 2 of 2

4. Androutsopoulos G, Kotsopoulos I, Decavalas G (2016) The role of lymphadenectomy in patients with endometrial cancer. J Gynecol Women's Health 1: 555573.

5. Abu-Rustum NR (2014) Sentinel lymph node mapping for endometrial cancer: a modern approach to surgical staging. J Natl Compr Canc Netw 12: 288-297.

6. Lopez-De la Manzanara Cano C, Cordero Garcia JM, Martin-Francisco C, Pascual-Ramirez J, Parra C, et al. (2014) Sentinel lymph node detection using 99 mTc combined with methylene blue cervical injection for endometrial cancer surgical management: a prospective study. Int J Gynecol Cancer 24: 1048-1053.

7. Cormier B, Rozenholc A, Gotlieb W, Plante M, Giede C (2015) Sentinel lymph node procedure in endometrial cancer: A systematic review and proposal for standardization of future research. Gynecol Oncol 138: 478-485.

8. Kang S, Yoo H, Hwang J, Lim M, Seo S, et al. (2011) Sentinel lymph node biopsy in endometrial cancer: meta-analysis of 26 studies. Gynecol Oncol 123: 522-527.

9. Abu-Rustum N, Khoury-Collado F, Pandit-Taskar N, Soslow R, Dao F, et al. (2009) Sentinel lymph node mapping for grade 1 endometrial cancer: is it the answer to the surgical staging dilemma? Gynecol Oncol 113: 163-169.
10. Ballester M, Dubernard G, Lecuru F, Heitz D, Mathevet P, et al. (2011) Detection rate and diagnostic accuracy of sentinel-node biopsy in early stage endometrial cancer: a prospective multicentre study (SENTIENDO). Lancet Oncol 12: 469-476.

11. Plante M, Touhami O, Trinh X, Renaud M, Sebastianelli A, et al. (2015) Sentinel node mapping with indocyanine green and endoscopic nearinfrared fluorescence imaging in endometrial cancer. A pilot study and review of the literature. Gynecol Oncol 137: 443-447.

12. Bezu C, Coutant C, Ballester M, Feron JG, Rouzier R, et al. (2010) Ultrastaging of lymph node in uterine cancers. J Exp Clin Cancer Res 29: 5 .

13. Ballester M, Dubernard G, Bats AS, Heitz D, Mathevet P, et al. (2012) Comparison of diagnostic accuracy of frozen section with imprint cytology for intraoperative examination of sentinel lymph node in earlystage endometrial cancer: results of Senti-Endo study. Ann Surg Oncol 19: 3515-3521.

14. Darai E, Dubernard G, Bats A, Heitz D, Mathevet P, et al. (2015) Sentinel node biopsy for the management of early stage endometrial cancer: longterm results of the SENTI-ENDO study. Gynecol Oncol 136: 54-59. 